\title{
New strategy of color and power doppler sonography combined with DMSA in the assessment of acute pyelonephritis in infants
}

Min Guang Chen ${ }^{1}$, Yan Yang ${ }^{2}$, Qing Yang ${ }^{1}$, Jie Qiu Zhuang ${ }^{1}$, Xiao Hua Ye ${ }^{3}$ and Wen Jie Zheng ${ }^{3 *}$

\begin{abstract}
Background: The purpose of this study was to evaluate the clinical value of color and power doppler sonography (CPDS) when combined it with 99mTc-dimercaptosuccinic acid scintigraphy (DMSA) in assessment of acute pyelonephritis (APN) in infants.

Methods: A total of 79 children with APN admitted to our hospital from June 2016 to Jan 2019 were enrolled, including 52 boys and 27 girls, age range 1 month to 3 years old. All cases followed the diagnostic criteria for acute pyelonephritis and excluded anatomical abnormalities of urinary system. All 79 patients were examined by urinary ultrasonography (US), CPDS, and DMSA within $48 \mathrm{~h}$ of fever and analyzed the clinical value of combining the two methods in the assessment of APN in infants.
\end{abstract}

Results: Among 79 children, urinary ultrasonography revealed 2 cases of renal cortical echo changes, both located in the upper pole of the kidney, 24 cases of kidney enlargement, and 1 case of left kidney shrinkage. Ninety-five kidneys were shown to be diseased with DMSA, while 105 kidneys abnormal by CPDS. The sensitivity of CPDS was $69.4 \%$, and the specificity was $38.1 \%$. In children younger than 6 months, the sensitivity of CPDS was $56.9 \%$, which was $84.2 \%$ in childeren between 6 months to 1 year, and 94.4\% from 1 to 3 years old, respectively. The corresponding specificity of CPDS was 44.1, 26.7, and 35.7\%. There was no significant correlation between CPDS levels and DMSA positive results. The abnormal rate of intermediate part in the kidneys was significantly lower than that in the upper and lower poles. Children with abnormal CPDS have a greater risk of renal scarring $(p<0.05)$.

Conclusion: Abnormalities detected by CPDS in a cohort of infants with APN poorly correlated with DMSA findings. But the sensitivity of CPDS is highly age-related, it can be used as a non-invasive helpful tool for early diagnosis of acute pyelonephritis in infants older than 6 months old.

Keywords: Color and power doppler sonography, 99mTc-dimercaptosuccinic acid scintigraphy, Acute pyelonephritis, Children, Kidney

\footnotetext{
* Correspondence: wzwjzheng@sina.com

${ }^{3}$ Department of Rheumatology, The Second Affiliated Hospital and Yuying

Children's Hospital of Wenzhou Medical University, Wenzhou 325027,

Zhejiang Province, China

Full list of author information is available at the end of the article
}

(C) The Author(s). 2021 Open Access This article is licensed under a Creative Commons Attribution 4.0 International License, which permits use, sharing, adaptation, distribution and reproduction in any medium or format, as long as you give appropriate credit to the original author(s) and the source, provide a link to the Creative Commons licence, and indicate if changes were made. The images or other third party material in this article are included in the article's Creative Commons. licence, unless indicated otherwise in a credit line to the material. If material is not included in the article's Creative Commons licence and your intended use is not permitted by statutory regulation or exceeds the permitted use, you will need to obtain permission directly from the copyright holder. To view a copy of this licence, visit http://creativecommons.org/licenses/by/4.0/ The Creative Commons Public Domain Dedication waiver (http://creativecommons.org/publicdomain/zero/1.0/) applies to the data made available in this article, unless otherwise stated in a credit line to the data. 


\section{Background}

Urinary tract infection(UTI) is a common disease in children. Although most of the patients with good prognosis, acute pyelonephritis (APN), if not be treated promptly, can lead to permanent renal scar formation, which is an important cause of chronic renal failure in young people. Therefore, it's important to identify APN early and give it positive treatment [1]. However, the accurate diagnosis of APN in children still quite difficult on the basis of clinical and laboratory findings alone [2, 3].

Since 1972, The technetium $99 \mathrm{~m}$ dimercaptosuccinic acid (DMSA) has been considered to be a gold standard for diagnosing APN at present [4]. However, there are still many disadvantages. Quite a few hospitals do not have this inspection equipment which is radiation and expensive. Therefore, a simple, inexpensive and nonradiative alternative method is required to help early identification and follow-up of children with APN.

Previous studies have shown that color and power doppler sonography (CPDS) can be used to evaluate renal cortical blood flow and contribute to the diagnosis of APN $[5,6]$, and compared the diagnostic difference between CPDS and DMSA in children with APN [7-12]. Some studies believe that doppler ultrasonography can be used as a predictive tool for permanent kidney damage following acute pyelonephritis [13], while others disagree $[14,15]$.

Most of the above studies focused on whether the CPDS could instead of DMSA for the diagnosis and follow-up of APN. But in our opinion, because CPDS can provide information such as renal cortical blood flow that DMSA and US cannot provide in the assessment of APN, negative DMSA sometimes cannot completely rule out APN [7]. Therefore, it may be better to make full use of the two inspections' respective advantages instead of replacing them. Thus, the purpose of this study was to assess the new role of CPDS in the application of APN in infants by prospective combined use of DMSA.

\section{Mathods}

\section{Study population}

We enrolled 79 children (including 52 boys and 27 girls) diagnosed with acute pyelonephritis, who were admitted to the Yuying Children's Hospital of Wenzhou Medical University from June 2016 to January 2019. All the patients were between 1 month and 3 years old. They all met the diagnosis criteria of APN [16], including positive urine culture or pyuria, body temperature above $38.5^{\circ} \mathrm{C}$, and raised peripheral blood leukocytes or C-reactive protein(CRP). Congenital malformations of the urinary system were excluded.

\section{Data collection}

All 79 patients underwent CPDS and DMSA examinations within $48 \mathrm{~h}$ of hospitalization. In order to ensure the accuracy of the test results, the CPDS of all children were individually checked by two senior sonographers who did not know the results of the DMSA test in advance. We operated the Siemens Sequoia 512 scanner for inspection. Ultrasonic probe frequency was 8-14 $\mathrm{MHz}$ for children under 3 months and $2.5-4 \mathrm{MHz}$ for children older than 3 months. An empirical 9-point semi-quantitative analysis was used as previously published [16]. The kidney was artificially divided into the upper pole, middle pole, and lower pole, and the parenchymal perfusion in each area was scored. No perfusion was scored as 0 and normal perfusion was 3 points. The sum of the three regions scores was the total score of each kidney. An 8-9 score was regarded CPDS negative, meanwhile, the score of CPDS positive was defined as less than eight.

The $99 \mathrm{mTc}$-DMSA examination was performed by a senior doctor of ECT who was unaware of the results of CPDS. We used SPECT vertex v60 ADAC (USA) for Tc$99 \mathrm{~m}$ DMSA renal scintigraphy. Each child was injected intravenously with $3.7 \mathrm{MBq} / \mathrm{kg} \quad(0.1 \mathrm{mCi} / \mathrm{kg}) \quad$ Tc $-99 \mathrm{~m}$ DMSA, Orbiter Siemens gamma camera was used to obtain images with 300,000-500,000 counts after 2-4 h. A same 9-point method for semi-quantitative analysis was selected which also divide the kidney into three regions of the upper pole, middle pole, and lower pole. No radioactive uptake was scored as 0 and normal uptake was 3 points. Greater than or equal to 8 points was considered DMSA negative, and a score of less than 8 was DMSA positive [17].

\section{Statistical analysis}

Comparisons between CPDS or DMSA findings were performed using Mann-Whitney nonparametric tests. The diagnostic values (sensitivity, specificity, predictive values, and accuracy) of CPDS and DMSA were assessed with contingency Tables. A $P$ value $\leq 0.05$ was considered significant.

\section{Results}

Comparison of US, CPDS, and DMSA results in children

All 79 patients met the APN diagnostic criteria. Urinary ultrasonography revealed 2 cases of renal cortical echo changes which both located in the upper pole of the

Table 1 Comparison of US and DMSA results in children

\begin{tabular}{llll}
\hline Group & US + & US - & Total \\
\hline DMSA + & 42 & 53 & 95 \\
DMSA - & 7 & 56 & 63 \\
Total & 49 & 109 & 158 \\
\hline
\end{tabular}

+ Positive, - Negative 
Table 2 Comparison of CPDS and DMSA results in children

\begin{tabular}{llll}
\hline Group & DMSA + & DMSA - & Total \\
\hline CPDS + & 66(SEN 69.4\%, PPV 62.8\%) & 39 & 105 \\
CPDS - & 29 & 24(SPE 38.1\%, NPV 45.3\%) & 53 \\
Total & 95 & 63 & 158
\end{tabular}

+ Positive, - Negative, SEN Sensitivity, SPE Specificity, PPV Positive predictive value, NPV Negative predictive value

kidney, 24 cases (48 kidneys) of kidney enlargement, and 1 case of left kidney shrinkage. For patients with APN, CPDS and DMSA can provide clear and valuable imaging results from different angles (see Fig. 1). Among 79 children (158 kidneys), 95 kidneys had abnormal DMSA and 105 had abnormal CPDS. The gross US changes were more apparent in the DMSA+ group $\left(\mathrm{x}^{2}=\right.$ 19.397, $P<0.01$ ) (See Table 1). The sensitivity, specificity, positive predictive value, and negative predictive value of CPDS as follow. (See Table 2).

\section{Comparison of CPDS and DMSA results in children with different age}

The sensitivity of CPDS detection was lower in children younger than 6 months of age, and the sensitivity increased with age. The sensitivity, specificity, positive predictive value, and negative predictive value of CPDS in different groups as follow. (See Table 3).

\section{Comparison of abnormal results of different kidney zones} There was no significant correlation between CPDS levels and DMSA positive results $(P>0.05)$. No matter CPDS or DMSA, the abnormal rate in midzone of kidney was significantly lower than that in the upper and lower poles (See Table 4,).

\section{Discussion}

APN is considered to be one of the most common and serious illnesses in infants. It may lead to permanent renal scar formation if it does not be recognized and be used by effective antibiotic treatment at the first $48 \mathrm{~h}$ after onset of the disease. A study has shown that the incidence of renal scar even up to $64 \%$ of affected pediatric kidneys [18]. Therefore, it is important to assess APN and treat it effectively as early as possible.

Imaging plays an essential role in the diagnosis of APN. Our data showed that a few children had normal white blood cells or normal CRP, but they had fever and abnormal urine tests. Therefore, it is crucial to identify APN by combining with imaging tests.

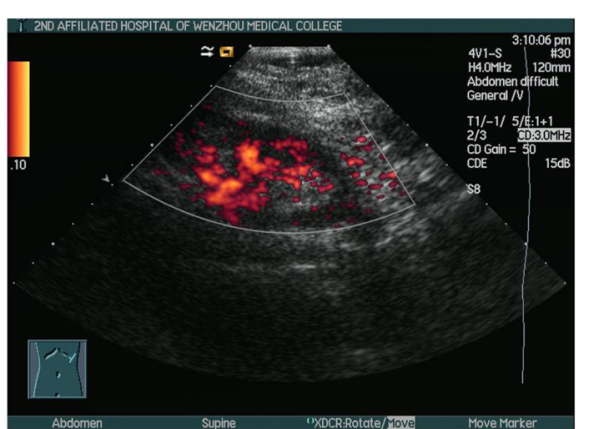

A

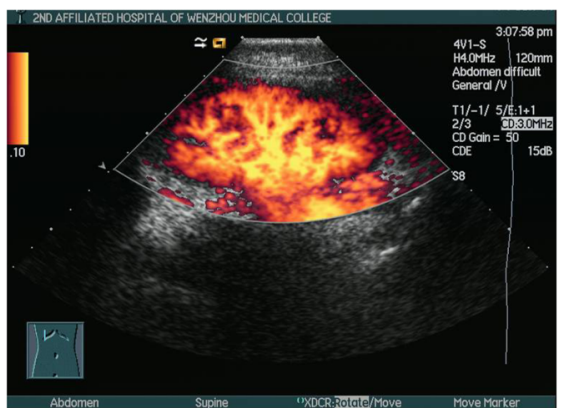

B

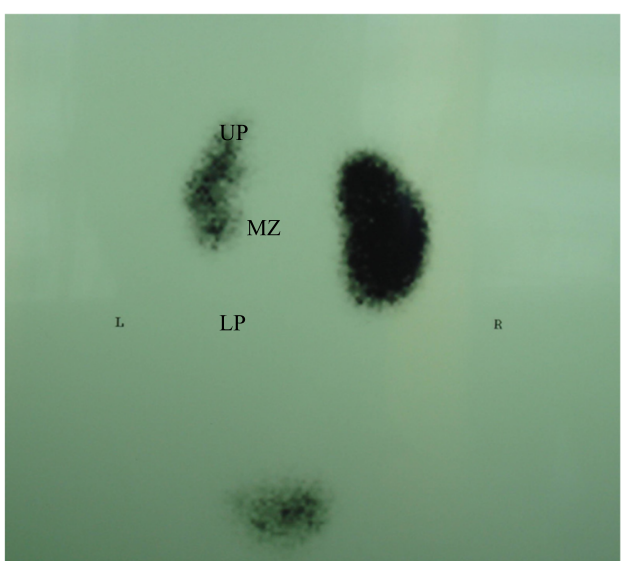

C

Fig. 1 Comparison of CPDS and DMSA results in infants with acute pyelonephritis. a, CPDS result of the left kidney, renal cortical blood flow was significantly decreased; b, CPDS result of the right kidney, renal cortical blood flow was normal; c, DMSA result, the upper pole, midzone, and lower pole of the left kidney were significantly sparse, but the right kidney was normal. UP, upper pole; MZ, midzone; LP, lower pole 
Table 3 Comparison of CPDS and DMSA results in children of different age groups (B)

\begin{tabular}{|c|c|c|c|c|c|c|c|c|c|}
\hline \multirow{2}{*}{$\begin{array}{l}\text { Group } \\
\text { Group }\end{array}$} & \multicolumn{3}{|c|}{ Group $1(<6 \mathrm{M})$} & \multicolumn{3}{|c|}{ Group 2(6 M <1Y) } & \multicolumn{3}{|c|}{ Group 3(1Y <3Y) } \\
\hline & DMSA + & DMSA - & Total & DMSA + & DMSA - & Total & DMSA + & DMSA - & Total \\
\hline \multirow[t]{2}{*}{ CPDS + } & 33 & 19 & 52 & 16 & 11 & 27 & 17 & 9 & 26 \\
\hline & \multicolumn{3}{|c|}{ (SEN 56.9\%; PPV 63.4\%) } & \multicolumn{3}{|c|}{ (SEN 84.2\%; PPV 59.2\%) } & \multicolumn{3}{|c|}{ (SEN 94.4\%; PPV 65.4) } \\
\hline \multirow[t]{2}{*}{ CPDS - } & 25 & 15 & 40 & 3 & 4 & 7 & 1 & 5 & 6 \\
\hline & \multicolumn{3}{|c|}{ (SPE 44.1\%; NPV 37.5\%) } & \multicolumn{3}{|c|}{ (SPE 26.7\%; NPV 57.1\%) } & \multicolumn{3}{|c|}{ (SPE 35.7\%; NPV 83.3\%) } \\
\hline Total & 58 & 34 & 92 & 19 & 15 & 34 & 18 & 14 & 32 \\
\hline
\end{tabular}

+ Positive, - Negative, SEN Sensitivity, SPE Specificity, PPV Positive predictive value, NPV Negative predictive value

Tc-99 m DMSA renal scintigraphy has been used for the detection and localization of APN inflammation with high sensitivity and specificity. And it is considered the gold standard for the diagnosis of APN. The invasiveness procedure, radiation exposure, and cost limit its clinical application. Meanwhile, negative DMSA results cannot completely rule out APN [7] . In this study, 7 patients had typical clinical manifestations of APN whose urine cultures were positive, peripheral blood leukocytes and CRP were significantly increased but had negative DMSA. Interestingly, 6 of these 7 cases showed positive CDPS. We diagnosed as APN based on clinical and CPDS and formulated corresponding treatment strategies in time for these patients. However, so far, early diagnosis of APN is still tricky in clinical practice.

Various types of renal vascular and renal parenchymal lesions are closely related to changes in intrarenal arterial hemodynamics. CPDS is developed on color Doppler technology and is superior to color doppler flow imaging in showing sensitivity and continuity of blood flow. Because this test is more sensitive to lowspeed blood flow, it reflects the integrated power from the reflected echo of the renal parenchyma [9]. Bude et al. [19] first reported the imaging ability of PDS on renal cortical blood perfusion. Since then, many studies have used PDS to study the effects of various kidney diseases on renal blood flow [15, 2022]. Previous studies have shown that CPDS can contributes to the diagnosis of APN, Anne Hitzel [7] has shown that although the predictive value of CPDS for renal scar is not high, the results of CPDS and DMSA are consistent in $81 \%$ of APN kidneys, suggesting that it has certain clinical application value. In view of the fact that the study did not cover all children and did not involve the exploration of specific parts of the infection, it is necessary to further explore.

Our study showed that the positive rate of DMSA is only $6 \%$ in patients older than 6 months with negative CPDS. Two double-blind controlled studies have also suggested that the specificity of CPDS for the diagnosis of APN is 85 to $95 \%$, and the sensitivity is 55 to $75 \%$, which is highly consistent with DMSA examination $[5,8]$. The data showed that the sensitive of CPDS is highly age-related. With the increase of age, the sensitivity of CPDS gradually increased. It may be related to a change in kidney blood flow caused by infant crying in an unsedated situation. In order to avoid deviations in the test results, infants should be tested in a quiet state.

Our study also found that there was no significant correlation between CPDS abnormal level and DMSA positive results, which was inconsistent with our preexpected results. We also observed that the location of renal abnormalities found by CPDS and DMSA is not the same. The pathophysiologic mechanism responsible for CPDS imaging abnormalities are focal ischemia due to vascular compression induced by interstitial edema [23]. While the uptake of $99 \mathrm{mTc}$ DMSA by the renal parenchyma is dependent on the glomerular perfusion and the transport function of the proximal tubule cell membrane. Since the detection mechanism of CPDS and DMSA is different when which be used to detect APN. DMSA abnormalities can not be judged from blood supply abnormalities or renal tubular epithelial cell damage, while CPDS can determine the blood supply of the kidneys. Just because CPDS can provide information such as renal cortical blood flow that DMSA and US cannot

Table 4 Comparison of results of different kidney sites

\begin{tabular}{|c|c|c|c|c|c|c|c|c|c|}
\hline \multirow[b]{2}{*}{ groups } & \multicolumn{3}{|c|}{ Upper pole } & \multicolumn{3}{|l|}{ Midzone } & \multicolumn{3}{|c|}{ Lower pole } \\
\hline & $\mathrm{DMSA}+$ & DMSA - & $\overline{\text { Total }}$ & DMSA + & DMSA - & Total & DMSA + & DMSA - & Total \\
\hline CPDS + & 43 & 35 & 78 & 6 & 21 & 27 & 31 & 39 & 70 \\
\hline CPDS - & 28 & 52 & 80 & 12 & 119 & 131 & 31 & 57 & 88 \\
\hline Total & 71 & 87 & 158 & 18 & 140 & 158 & 62 & 96 & 158 \\
\hline
\end{tabular}


provide in the assessment of APN, these two methods have good complementarity.

\section{Conclusion}

It is not necessary to focus on replacing DMSA with CPDS in clinical practice, but to synergistically utilize their respective advantages to improve the clinical APN assessment level. The CPDS can be used as a noninvasive helpful tool for early diagnosis of acute pyelonephritis in infants older than 6 months old, especially when some families refuse DMSA inspection due to radiation exposure.

\section{Abbreviations}

CPDS: Color and power doppler sonography; DMSA: 99mTcdimercaptosuccinic acid scintigraphy;" APN: Acute pyelonephritis; US: Urinary ultrasonography

\section{Acknowledgements}

The authors wish to thank the staff of the department of Nephrology,Rheumatology, Ultrasonics for their important contributions. The results presented in this paper have not been published previously in whole or part.

\section{Authors' contributions}

MGC participated in research design, data collection, data analysis and writing of the article. YY participated in data collection and operating ultrasound examination of all patients. OY participated. in research design and writing of the article. JQZ participated in data collection and writing of the article. XHY, participated in data collection and writing of the article. WJZ participated in research design, data collection, data analysis and writing of the article. All authors read and approved the final manuscript.

\section{Funding}

No funding was received for this work.

\section{Availability of data and materials}

The datasets used and/or analyzed during the current study are available from the corresponding author on reasonable request.

\section{Declarations}

\section{Ethics approval and consent to participate}

This retrospective study was reviewed and approved by the Institutional Ethics Committee from The Second Affiliated Hospital and Yuying Children's Hospital of Wenzhou Medical University, China. The Medical Department of Second Affiliated Hospital and Yuying Children's Hospital authorized us to access and use these medical records. As this was a retrospective study, written consent to participate from the study subjects was not required.

\section{Consent for publication}

Not applicable.

\section{Competing interests}

The authors declare no conflicts of interest or competing interests.

\section{Author details}

'Department of Nephrology, The Second Affiliated Hospital and Yuying Children's Hospital of Wenzhou Medical University, Wenzhou 325027, Zhejiang Province, China. ${ }^{2}$ Department of Ultrasonics, The Second Affiliated Hospital and Yuying Children's Hospital of Wenzhou Medical University, Wenzhou 325027, Zhejiang Province, China. ${ }^{3}$ Department of Rheumatology, The Second Affiliated Hospital and Yuying Children's Hospital of Wenzhou Medical University, Wenzhou 325027, Zhejiang Province, China.
Received: 25 June 2019 Accepted: 5 May 2021

Published online: 17 May 2021

\section{References}

1. Jacobson SH, Eklof O, Lins LE, Wikstad I, Winberg J. Long-term prognosis of post-infectious renal scarring in relation to radiological findings in childhood-a 27-year follow-up. Pediatr Nephrol. 1992;6:19-24.

2. Hoberman A, Chao HP, Keller DM, Hickey R, Davis HW, Ellis D. Prevalence of urinary tract infection in febrile infants. J Pediatr. 1993;123:17-23.

3. Cornu C, Cochat P, Collet J-P, Delair S, Haugh MC, Rolland C. Survey of the attitudes to management of acute pyelonephritis in children. Pediatr Nephrol. 1994;8:275-7

4. Jakobsson B, Nolstedt L, Svensson L, Söderlundh S, Berg U. Tc-99m DMSA scan in the diagnosis of acute pyelonephritis in children: relation to clinical and radiological findings. Pediatr Nephrol. 1992;6:328-34.

5. Halevy R, Smolkin V, Bykov S, Chervinsky L, Sakran W, Koren A. Power Doppler ultrasonography in the diagnosis of acute childhood pyelonephritis. Pediatr Nephrol. 2004;19(9):987-91.

6. Basiratnia M, Noohi AH, Lotfi M, Alavi MS. Power Doppler sonographic evaluation of acute childhood pyelonephritis. Pediatr Nephrol. 2006;21(12): 1854-7

7. Hitzel A, Liard A, Véra P, Manrique A, Ménard JF, Dacher JN. Color and power Doppler sonography versus DMSA scintigraphy in acute pyelonephritis and in prediction of renal scarring. J Nucl Med. 2002;43(1): 27-32.

8. Stogianni A, Nikolopoulos P, Oikonomou I, Gatzola M, Balaris V, Farmakiotis D, et al. Childhood acute pyelonephritis: comparison of power Doppler sonography and Tc-DMSA scintigraphy. Pediatr Radiol. 2007;37(7):685-90.

9. Bykov S, Chervinsky L, Smolkin V, Halevi R, Garty I. Power Doppler sonography versus Tc-99m DMSA scintigraphy for diagnosing acute pyelonephritis in children: are these two methods comparable? Clin Nucl Med. 2003:28(3):198-203.

10. Yoo JM, Koh JS, Han CH, Lee SL, Ha US, Kang SH, et al. Diagnosing acute pyelonephritis with CT, Tc-DMSA SPECT, and Doppler ultrasound: a comparative study. Korean J Urol. 2010;51(4):260-5.

11. Mohkam M, Maham S, Rahmani A, Naghi I, Otokesh B, Raiiati H, et al. Technetium Tc 99m dimercaptosuccinic acid renal scintigraphy in children with acute pyelonephritis: correlation with other imaging tests. Iran J Kidney Dis. 2010:4(4):297-301.

12. Ayazi P, Mahyar A, Noroozian E, Esmailzadehha N, Barikani A. Comparison of renal ultrasonography and dimercaptosuccinic acid renal scintigraphy in febrile urinary tract infection. Infez Med. 2015;23(4):323-9.

13. Mohammadjafari $H$, Aalaee A, Salehifar E, Shiri A, Khademloo M, Shahmohammadi S. Doppler ultrasonography as a predictive tool for permanent kidney damage following acute pyelonephritis: comparison with dimercaptosuccinic acid scintigraphy. Iran J Kidney Dis. 2011;5(6):386-91.

14. Narchi H, Donovan R. Renal power Doppler ultrasound does not predict renal scarring after urinary tract infection. Scott Med J. 2008;53(4):7-10.

15. Shajari A, Nafisi-Moghadam R, Malek M, Smaili A, Fallah M, Pahlusi A. Renal power Doppler ultrasonographic evaluation of children with acute pyelonephritis. Acta Med Iran. 2011;49(10):659-62.

16. Zhu H, Chen M, Luo H, Pan Y, Zheng W, Yang Y. Semiquantitative analysis of power doppler ultrasonography versus Tc-99m DMSA scintigraphy in diagnostic and severity assessment of acute childhood pyelonephritis. Transl Pediatr. 2020;9(4):487-95.

17. Hitzel A, Liard A, Dacher JN, et al. Quantitative analysis of $99 \mathrm{mTC}-\mathrm{DMSA}$ during acute pyelonephritis for prediction of longterm renal scarring. J Nucl Med. 2004:45:285-9.

18. Benador D, Benador N, Slosman DO, Nussle D, Mermillod B, Girardin E. Cortical scintigraphy in the evaluation of renal parenchymal changes in children with pyelonephritis. J Pediatr. 1994;124(1):17-20.

19. Bude RO, Rubin JM, Adler RS. Power versus conventional color Doppler stenography: comparison in the depiction of normal intrarenal vasculature. Radiology. 1994;192:777-80.

20. Bernardes LS, Francisco RP, Saada J, Salomon R, Ruano R, Lortad-Jacob S, et al. Quantitative analysis of renal vaseularization in fetuses with urinary tract obstruction by three-dimensional power-Doppler. Am J Obstet Gynecol. 2011;205:572

21. Vreju F, Ciurea M, Rosu A, Musetescu A, Grecu D, Ciurea P. Power Doppler sonography, a non-invasive method of assessment of the synovial 
inflammation in patients with early rheumatoid arthritis. Rom J Morphol Embry. 2011;52:637-43.

22. Miyajima T, Yokoyama H, Taira H, Tsuji Y. Quantitative estimation of renal blood flow by power Doppler ultrasonography in renovascular hypertensive dogs. Kidney Int. 2005;68:2781-6.

23. Majd M, Nussbaum Blask AR, Markle BM, Shalaby-Rana E, Pohl HG, Park JS, et al. Acute pyelonephritis: comparison of diagnosis with 99mTc-DMSA, SPECT, spiral CT, MR imaging, and power Doppler US in an experimental pig model. Radiology. 2001;218(1):101-8.

\section{Publisher's Note}

Springer Nature remains neutral with regard to jurisdictional claims in published maps and institutional affiliations.

Ready to submit your research? Choose BMC and benefit from:

- fast, convenient online submission

- thorough peer review by experienced researchers in your field

- rapid publication on acceptance

- support for research data, including large and complex data types

- gold Open Access which fosters wider collaboration and increased citations

- maximum visibility for your research: over $100 \mathrm{M}$ website views per year

At $\mathrm{BMC}$, research is always in progress.

Learn more biomedcentral.com/submissions 